\section{AN ANALYSIS DF PLANT \\ BLINDNESS IN TURKISH \\ TEXTBᄆDKS USED AT THE \\ BASIC EDUCATION LEVEL}

\author{
Berat Ahi, \\ Volkan Atasoy, \\ Sibel Balci
}

\section{Introduction}

Although the Earth is often described as the "blue planet", it is an irrefutable fact that we live in a green world. Plants serve critical functions such as being primary producers in food chain, providing main supply of oxygen for organisms, playing an active role in the water cycle, and holding the soil together with their roots. People are intertwined with plants at every point of their daily lives; plants are vital to humanity in terms of both social activities to relax and their aesthetic appeal in architecture and art, as well as commercial activities, healthcare and food. In short, it is not possible to discuss life on Earth without mentioning plants.

Unfortunately, not enough emphasis is placed on the importance of plants. Over 1,500 plants are currently classified as high priority for protection on the International Union for Conservation of Nature (IUCN) Red List (2016). In the future, it will be very difficult for plants to continue to support life on Earth. Wandersee and Schussler (1999) concluded that the reason for this is a low level of awareness, which is the result of people not having enough knowledge about plants. The meta-analysis of Allum, Sturgis, Tabouraz and Brunton-Smith (2008) which included research from Turkey showed that there is a significant positive relationship among scientific knowledge with the attitudes and behaviors. Considering the related research, it can be accepted that the low level of knowledge and awareness about plants are the sources of "plant blindness". Plant blindness is defined as the lack of ability on the part of humans to: (a) see and recognize the surrounding vegetation; (b) understand the importance of plants for human life in the biosphere; and (c) recognize aesthetics of plants in their life cycles (Wandersee \& Schussler, $1999 ; 2001)$. In addition, plant-blind people are said to assign an inferior role to plants compared with animals and to expose them to adverse situations (Wandersee\&Schussler, 1999; 2001). Balas and Momsen (2014) have revealed

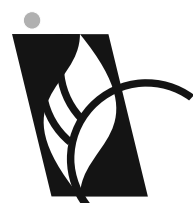

J O U R N A L

$\mathrm{OF} \bullet \mathrm{B}$ A L T I C

$S$ C I E N C E

EDUCATION

ISSN 1648-3898

/Print/ ISSN 2538-7138 /Online/

Abstract. The importance of plants is not as clearly understood as that of animals. This lack of attention is called "plant blindness" and is considered one of the most important problems in biology education. Textbooks do not put much emphasis on plants and, therefore, they may contribute to plant blindness. In this research, ten textbooks used for teaching at the basic education level in Turkey were analyzed for plant blindness using the document analysis method. The words and photographs associated with plants and animals were analyzed. The data analysis did not find any evidence that could lead to a conclusion of plant blindness based on the text and photos of these textbooks. However, if the number of plant and animal species covered is increased, and more words and photos are used to introduce these species, children will become more familiar with plants and animals. Besides textbooks, other educational tools can be analyzed in terms of plant blindness to expand on the related literature.

Keywords: plant blindness, photograph in textbook, document analysis, written text.

Berat Ahi, Volkan Atasoy Kastamonu University, Turkey Sibel Balci TED University, Turkey 
cognitive evidence for plant blindness. In their research, they found that participants can remember animals more easily than plants and retain their memory of animals for a longer time, even if they have received botany training. A similar situation was found in the research by Schussler and Olzak (2008). Possible explanations for this situation include that the schemas formed for plants are destroyed much faster in the mind, and that it is more difficult to make these schemas permanent. Moreover, Lindemann-Matthies (2005) and Balding and Williams (2016) think that children in early childhood perceive plants as lifeless because they show limited vitality (such as movement). Uno $(1994 ; 2009)$ suggested that the most important cause of plant blindness is education. Uno (1994) proposes that curricula (particularly biology courses), teachers and textbooks do not put much emphasis on plants. Thus, it is inevitable that plant blindness emerges as a major problem of understanding the importance of plants for biosphere (Uno, 2009).

Biology education is as important a part of early childhood education as it is at other levels of education (Baird, Lazarowitz\& Allman, 1984). Wandersee (1986) found that students are more interested in information and prefer research about animals. One of the most frequently cited reasons for this is that plants are not adequately represented as content in education (Patrick \& Tunnicliffe, 2011; Schussler \& Winslow, 2006; Tunnicliffe \& Reiss, 2000). As a reflection of this, when students are asked to list living creatures, they might not include plants in the first ten (Yörek, Şahin \& Aydın, 2009).

Many components of early childhood education need to be examined before this situation can be corrected. During the early childhood education process, it is essential for the students to have direct experience of the plants inside and outside the classroom, and it is also a useful method to prevent plant blindness (Strgar, 2007). Apart from these, different educational materials should be used. Books are very significant at this stage (Gatt, Tunnicliffe, Borg \&Lautier, 2007). While Tunnicliffe and Reiss (2000) emphasize the importance of direct observation, they also pointed out that it is very crucial to give information about plants indirectly using books. Moreover, Patrick and Tunnicliffe (2011) show the importance of the books as a result of the fact that the rate of seeing the plants in the book is high among the children.

Textbooks have become an important part of early childhood education over the last 20 years (Prochner \& Woitte, 2013). Textbooks are not just a source of information but also provide an insight into the culture, beliefs, values and perspectives of the societies in which they are written (Issit, 2004; Newton \& Newton, 2006), and contain political, economic and cultural reflections of the time at which they were written (Ferguson, Collison, Power \&Stevenson, 2006). For this reason, understanding of the contents of textbooks will help us to make sense of that society's viewpoints (the general tendency) of different subjects.

Textbooks do not solely educate using written text. It is also necessary to have images (graphics, illustrations, photographs, etc.). Books with visual content are particularly important for the development of the skills required for early literacy, and provide cognitive flexibility to children in terms of comprehending the information the book contains, summarizing and making guesses (Mantzicopoulos \& Patrick, 2010). In addition, visual aids allow information to be organized in different ways (Lemoni, Stamou \& Stamou, 2011). Images can also contain messages that are not contained in the written text (Golos, Moses \&Wolbers, 2012).

The existing body of literature that examines textbooks as educational materials for early childhood is not sufficient (Lemoni, Lefkaditou, Stamou, Schizas \& Stamou, 2013; Martinez-Bello \&Martinez-Bello, 2016). There are studies that demonstrate the effectiveness of visuals in textbooks pedagogically (Dimopoulos, Kouladis\&Sklaveniti, 2003; Sullivan, 2008). There are also studies that examine the contents of textbooks in terms of different concepts (text, etc.) (Golos, Moses \&Wolbers, 2012; Lemoni et al., 2013; Miralles-Martinez \&AlfagemeGonzalez, 2010). There are very few studies on the textual content of textbooks, therefore, to address this gap in the literature, this research aims to focus on text while examining plant blindness. The research that examines textbooks in terms of plant blindness is also limited. Link-Perez, Dollo, Weber and Schussler (2010) examined two different US science teaching textbooks in terms of plant and animal visuals, and found that the textbooks had a zoo-centric viewpoint. In a similar research, it was concluded that, in primary school science textbooks, nearly twice as much space was allocated to animals compared with plants (Schussler, Link-Perez, Weber \& Dollo, 2010). On the other hand, using more animal visuals in textbooks does not mean that animal species dominate plant species. This situation can be the result from usage of more repetition of images related to animal species than plant species. The research of plant blindness in textbooks used in different societies will make important contributions to the literature. Turkey is one of countries in which plant blindness can be observed at early childhood education level (Ahi, Kurt \& Balci, 2017; Balci, Ahi \& Sun, 2017). This research has been done in the light of the importance of investigating the causes of this issue. Based on the idea that textbooks reflect the cultural 
viewpoints of the societies they belong to (Lee \& McMullen, 2006), it is believed that the analysis of the written and visual contents of the textbooks used in the early childhood education in Turkey will yield important findings for environmental education, sustainability. Thus, this research seeks answers to the following questions:

- Is there a difference between the uses of words related to animals and plants in the text in the textbooks?

There are several definitions of "plants" such as embryophytes (land plants), streptophytes and green plants. Embryophytes mean embryo protected by tissues of the parent plant. By adding certain green algae groups to embryophytes, streptophytes and green plants are called. In the present research, embrophytes are used as to define plants. General characteristic of embryophytes includes using of chlorophyll in the photosynthesis, producing starch as storage material and having cellulose in cell wall. Embrophytes are divided into two main groups; nonvascular plant, and vascular plants including seedless and seed plants. In addition, seed plants have two subcategories, gymnosperm and angiosperm (Sadava, Heller, Orians Purves, \& Hillis, 2006).

Animals are classified into two main categories: invertebrate and vertebrate animals. Invertebrate animals include sponges, coelenterate, annelid, mollusks, artropods, Echinodermata, whereas vertebrate animals have groups such as fish, amphibian, reptiles, birds and mammals.

- What is the difference between the numbers of the plant and animal photographs used in the textbooks?

- Is there a difference between the labeling of the plant and animal photographs in the textbooks?

\section{Methodology of Research}

\section{General Background}

The aim of the current research is to examine plant blindness issue in Turkish textbooks. For this purpose, 10 textbooks used at basic education level were analyzed by document analysis technique. Words and photographs related to plants and animals in the textbooks were investigated. Data of the analysis were presented by using frequency and percentage value. In order to increase trustworthiness of the research, two researchers separately did the analysis of the textbooks; then, their findings were compared and contrasted. In order to determine the ratio of inter-rater agreement, Kappa coefficient was calculated. This research covered a period of three months including gathering and analyzing textbooks.

\section{Research Design}

In this research, the textbooks were analyzed in terms of the space allocated to animals and plants using the document analysis technique, which is a qualitative research method (Merriam, 2009). In the textbooks, words and photographs related to the plants and animals were investigated. The textbooks (except for the pre-school education textbook) are divided into units and units are divided into topics. Plants and animals may feature in topics that are not directly related to them, therefore the texts and photographs of all the units were analyzed in detail.

Photographs in the textbooks were analyzed in the research because they reflect the real world and its fauna and flora just as they are (Pozzer\& Roth, 2003). Diagrams, graphics, drawings or any other images were not included in the analysis. The reason of that, diagrams and graphs are artificial products which are used as a means of summarizing information. Moreover, they may include personal opinions of the drawers; therefore, they were not taken into consideration for this research.

\section{Research Group}

Textbooks used in Turkish educational establishments are sent to the Board of Education affiliated to the Ministry of National Education after being written by subject area specialists. Here, textbooks are reviewed by the relevant commissions and accepted for use for a 5-year period after approval. Approved textbooks are printed by various publishing houses and distributed to students free of charge by the state. In this research, a total of the 10 textbooks which have been approved for teaching since 2016 used in basic education were examined. 
"Basic education" is the first stage of education in Turkey, starting with pre-school education and ending at the end of the 4th grade of primary school. The latest figures report that a total of 11,101,180 students were studying at all education levels in Turkey during the first semester of the 2016-2017 academic year. Of these students, $10.0 \%$ (1,315,854 children) are in pre-school education and $42.9 \%(4,970,160$ students) are in elementary school education (MEB, 2017).

The analyzed textbooks, except for the pre-school education textbook, contain different subject areas. Only textbooks for courses with content related to plants were included, i.e., life sciences, natural sciences and social sciences. There is only one pre-school education textbook included in the research. At the elementary education level, life sciences courses are taught in the 1st, 2nd and 3rd grades; natural sciences courses are taught in the 3rd and 4th grades; and social sciences courses are taught in the 4th grade. Thus, a total of 10 textbooks, including one pre-school textbook, two 1st grade life sciences textbooks, two 2nd grade life sciences textbooks, two 3 rd grade life sciences textbooks, two 4th grade life sciences textbooks and one 4th grade social sciences textbook, were analyzed.

\section{Text Analysis}

A general analysis of the use of words related to plants and animals was performed, and the results were recorded in a chart. The words were then divided into subcategories depending on their types. The seven-level system for the analysis of photographs, developed by Link-Perez, Dollo, Weber and Schussler (2010), was adapted for the analysis of the words in the text. As two of the seven levels are specific to the analysis of photographs, they were not used in the analysis of the text (Table 1).

Table 1. Text analysis code chart.

\begin{tabular}{cll}
\hline Specificity level & Stage name & Definition \\
\hline Level 1 & Broadest & Only the words including "plants" or "animals" \\
Level 2 & Medium level & Includes a general category related to the organism, e.g. mammal, bird. \\
Level 3 & Specific & $\begin{array}{l}\text { Indicates a specific example of an organism, including the family, genus or species to which } \\
\text { the organism belongs, e.g., zebra, oak. }\end{array}$ \\
Part & Part/organ & $\begin{array}{l}\text { Includes a part or an organ of the organism, e.g., branch, wing. } \\
\text { Form }\end{array}$ \\
& Form of life & $\begin{array}{l}\text { Where only the life-form, such as tree, seedling, shrub, is provided. This category is at the } \\
\text { same time the cultural reflection of biological taxonomy. }\end{array}$ \\
\hline
\end{tabular}

\section{Photograph Analysis}

The photographs of plants and animals in the textbooks were examined from two perspectives: the subject and the specificity of the photo (label). A code chart was formed to analyze the photos systematically and in detail from these two perspectives. The coding was carried out in line with the following principles.

Principle 1: The object of the photo. The focal point of the photograph should be the plant or animal; all the photos not complying with this criterion were excluded. The photograph can be labeled as one of four types:"a photograph with animal";"a photograph with plant"; "a photograph with landscape"; or "a photograph with both plant and animal". When there are one or more plants or animals in photographs, it is labeled as a "photograph with animal or plant". "A photograph with landscape" should include a collection of different species of plants rather than one species or group of plants. The category of "a photograph with both plant and animal" is used to refer to a single photograph in which both plant(s) and animal(s) are equal and distinct. Such photographs generally depict a close interaction between a plant and an animal, for example, a bee on a flower.

Principle 2: Specificity of the photo (label).This feature is designed to indicate the specificity level of the label (i.e., the name) created for plant and animal in a photo. When a photo has a specific title or label, then it is classified as "labeled". If there is no label belonging to a photograph, then it is described as "unlabeled". In the determination of the specificity level, the seven-level system developed by Link-Perez, Dollo, Weber and Schussler (2010) was used (Table 2). 
Table 2. Photograph definition code chart.

\begin{tabular}{|c|c|c|}
\hline Specificity level & Stage name & Definition \\
\hline Level 0 & Unlabeled & There is no explanation for the photograph. \\
\hline Level 1 & Comprehensive & Only includes information which belongs to, e.g., plant, animal. \\
\hline Level 2 & & Includes a general category that applies to the organism, e.g., mammal. \\
\hline Level 3 & Specific & Includes the family or species to which the organism belongs, e.g., elephant, pine tree. \\
\hline Level N/A & Not applicable & $\begin{array}{l}\text { Includes labels related to the ecosystem or a concept, e.g., photosynthesis, desert, summer } \\
\text { or seed. However, it does not include the label specific to the organism itself. This category } \\
\text { allows the documentation of photographs without affecting the labeling analysis of organisms. }\end{array}$ \\
\hline Part & Part/organ & $\begin{array}{l}\text { A part or an organ of the organism is depicted, e.g., flower, seed, fin. However, there is no } \\
\text { identifier for the organism. }\end{array}$ \\
\hline Form & Life-form & $\begin{array}{l}\text { Includes the name of the life-form, e.g., tree, seedling or shrub of the organism. This category } \\
\text { is also a cultural reflection of biological taxonomy. }\end{array}$ \\
\hline
\end{tabular}

\section{Data Analysis}

The data are made up of text and photographs. In the data analysis process, text was analyzed first. Plant and animal names in the text were recorded in the code chart using specificity levels. The codes in the chart were then categorized as belonging to plants or animals. The same process was followed for the analysis of the photographs. The obtained data were digitized and presented in tables.

To increase the reliability and validity of the research, the data analysis was conducted separately by two researchers. Establishment of the code chart was performed by the researchers independently and then they came together to discuss. The inter-rater agreement was calculated for both the text and the photograph analysis using the Kappa coefficient; the Kappa values were 0.86 and 0.88 , respectively. Finally, the code chart was also submitted for the scrutiny of a third researcher and another expert in biology education.

\section{Results of Research}

\section{Text in Textbooks}

The texts in 10 textbooks used in pre-schools and primary schools were examined. The analysis showed that the text included more words related to plants than animals (Table 3). Of 975 words, $62.5 \%$ were associated with plants and $37.5 \%$ were associated with animals. However, the word "animal" was used more than the word "plant" (54.1\% versus $45.9 \%)$. Similarly, general categories of animals (e.g., fish, insect) outnumbered that of plants (e.g., grass, tree). At Level 3, plant species, such as pine tree or lily, were mentioned more than animal species, such as butterfly or cow (61.5\% versus $38.5 \%$ ). It was also observed that the words for parts/organs of plants (e.g., flower, seed) were used seven times more than those for animals (e.g., wing). The use of life-form terminology was found for plants but not for animals. There were no clear differences between the usage of words related to plants and animals with respect to the grade or field of the textbooks.

Table 3. Frequency of use of words related to plants and animals across textbooks.

\begin{tabular}{|c|c|c|c|c|c|c|c|}
\hline \multicolumn{2}{|c|}{ Textbooks } & \multicolumn{6}{|c|}{ Plant/Animals } \\
\hline Grade & Field & Level 1 & Level 2 & Level 3 & Part/organ & Form & Total \\
\hline $1 \mathrm{st}$ & Social studies & $16 / 15$ & $2 / 13$ & $32 / 15$ & $15 / 1$ & $25 / 0$ & $90 / 44$ \\
\hline $1 \mathrm{st}$ & Social studies & $29 / 38$ & $1 / 22$ & $45 / 7$ & $10 / 0$ & $32 / 0$ & $117 / 67$ \\
\hline 2nd & Social studies & $4 / 10$ & $0 / 3$ & $1 / 27$ & $3 / 5$ & $23 / 0$ & $31 / 45$ \\
\hline $3 r d$ & Social studies & $0 / 1$ & $0 / 2$ & $2 / 2$ & $0 / 0$ & $2 / 0$ & $4 / 5$ \\
\hline
\end{tabular}




\begin{tabular}{cccccccc}
\hline \multicolumn{2}{c}{ Textbooks } & \multicolumn{7}{c}{ Plant/Animals } \\
\hline \multirow{2}{*}{ Grade } & Field & Level 1 & Level 2 & Level 3 & Part/organ & \multirow{2}{*}{ Form } & Total \\
\hline 3rd & Science & $4 / 6$ & $0 / 2$ & $4 / 7$ & $1 / 0$ & $5 / 0$ & $14 / 15$ \\
3rd & Science & $30 / 22$ & $0 / 19$ & $73 / 52$ & $18 / 1$ & $36 / 0$ & $157 / 94$ \\
4th & science & $0 / 2$ & $0 / 3$ & $1 / 5$ & $0 / 0$ & $1 / 0$ & $2 / 10$ \\
4th & Science & $9 / 10$ & $0 / 9$ & $51 / 21$ & $0 / 0$ & $49 / 0$ & $109 / 40$ \\
4th & Social studies & $3 / 7$ & $0 / 2$ & $24 / 10$ & $1 / 0$ & $11 / 0$ & $39 / 19$ \\
Pre-school & - & $0 / 1$ & $0 / 10$ & $24 / 15$ & $2 / 0$ & $21 / 0$ & $47 / 26$ \\
\hline Total & & $95 / 112$ & $3 / 85$ & $257 / 161$ & $50 / 7$ & $205 / 0$ & $610 / 365$ \\
\hline
\end{tabular}

Animals that were specifically mentioned included: 27 invertebrate animals (one coelenterate, six annelids, two mollusks and 18 arthropods); and 134 vertebrate animals (nine fish, one amphibian, 27 reptiles, 30 birds and 81 mammals). Of these specific names, there were 11 different invertebrate types (one coelenterate, one annelid, two mollusks and seven arthropods), 42 vertebrate types (five fish, one amphibian, three reptiles, 11 birds and 22 mammals). Of 257 plant species named in the textbooks, there was one non-vascular plant (moss), one gymnosperm (oak), and 254 angiosperms including two monocotyledons (wheat and palm tree) and 47 dicotyledons (e.g., apple, tulip). It was found that animals and plants have nearly equal representation in terms of diversity in the text. When it comes to repetition of specific plant and animal names, it was seen that there is no dominance: 29 plant species and 30 animal species were repeated. While fruits (e.g., apple tree, orange tree), and vegetables (e.g., tomato, potato) were the plant terms most often repeated, domestic animals (e.g., cat, dog) were the most dominant animal terms used.

\section{Images in Textbooks}

As shown in Table 4, there were 536 photographs in the textbooks. Of these, $49.8 \%$ were plant photographs and $35.3 \%$ were animal photographs, highlighting a disparity between the two subjects in favor of use of plant images. When compared with plants and animal images, landscape and dual subject images were used less often in the textbooks: the proportions of landscape and dual subject images were $6.52 \%$ and $8.38 \%$, respectively. The use of animal and plant subject images did not differ across grade or field of the textbooks.

Table 4. Frequencies of subject image across textbooks.

\begin{tabular}{|c|c|c|c|c|c|c|}
\hline \multicolumn{3}{|c|}{ Textbooks } & \multicolumn{2}{|c|}{ Subject of image } & \multirow[b]{2}{*}{ Dual } & \multirow[b]{2}{*}{ Total } \\
\hline Grade & Field & Plant & Animals & Landscape & & \\
\hline $1 \mathrm{st}$ & Social studies & 36 & 7 & 7 & 3 & 53 \\
\hline $1 \mathrm{st}$ & Social studies & 99 & 61 & 8 & 4 & 172 \\
\hline 2nd & Social studies & 4 & 15 & 2 & 7 & 28 \\
\hline $3 r d$ & Social studies & 1 & 0 & 2 & 4 & 7 \\
\hline $3 r d$ & Science & 4 & 14 & 5 & 8 & 31 \\
\hline $3 r d$ & Science & 45 & 44 & 11 & 3 & 103 \\
\hline 4th & Science & 17 & 11 & 0 & 1 & 29 \\
\hline 4th & Science & 18 & 13 & 0 & 5 & 36 \\
\hline 4th & Social studies & 17 & 10 & 0 & 0 & 27 \\
\hline Pre-school & - & 26 & 14 & 0 & 13 & 53 \\
\hline Total & & 267 & 189 & 35 & 45 & 536 \\
\hline
\end{tabular}


Another major finding of the present research was that unlabeled images for plant and animals were dominant in the textbooks (Table 5). When looking at the percentages of labeled images for plant and animals separately, it was seen that both were roughly equivalent (32\%). In the textbooks, among the plant images, some photographs were labeled as the part of plants (e.g., leaf) and life-forms (e.g., tree) while there were no images where the organ/part or life-form of the animal was named. There are no plant or animal labels in the textbooks. In addition, Level 2 intermediate labels for plant and animals (e.g., invertebrate, mammals, mosses, ferns) were not used in the textbooks. In that category, only one image related to animals was labeled as bird. Photographs categorized as landscape or dual subject specificity were not labeled.

Table 5. Frequency of subject image across specificity levels.

\begin{tabular}{lccc}
\hline & & \multicolumn{2}{c}{ Subject of image } \\
\cline { 2 - 4 } Specificity of image label & Plant & Animal & Landscape \\
\cline { 2 - 4 } & 86 & 61 & - \\
Specific (Level 3) & 0 & 1 & - \\
Intermediate (Level 2) & 0 & 0 & - \\
Broadest (Level 1) & 168 & 127 & 35 \\
Unlabeled (level 0) & 2 & 0 & - \\
Part & 11 & 0 & - \\
Life-form & & -
\end{tabular}

When the data in Level 3 were examined in detail, it was observed that specifically labeled plant photographs comprised five gymnosperms and 81 angiosperms, including three monocotyledons and 61 dicotyledons. No labeled non-vascular plants were found. Animal photographs included 15 invertebrate animals (two coelenterates, one mollusk and 12 arthropods) and 46 vertebrate animals (six fish, one amphibian, five reptiles, 19 birds and 15 mammals). Of these photographs, there were 10 different invertebrate types (two coelenterates, one mollusk and seven arthropods), and 32 vertebrate types (four fish, one amphibian, three reptiles, 13 birds and 11 mammals). Representation of plant species outnumbered that of animal species in the textbooks. Concerning the repetition of plant and animal subjects, 11 plant species (e.g., cherry, apple) and 13 animal species (e.g., dog, turtle, cat) were repeated. There was no dominance from plants or animals with respect to repetition.

\section{Discussion}

The findings of the research revealed that words related to plants are used more frequently than words related to the animals in the text of the analyzed textbooks. However, when the words "plant" and "animal" were compared alone, it was found that the word "animal" is used more frequently. While more space is allocated to plant species than animal species, general categories to which plants belong in terms of classification are used less frequently than the general categories to which animals belong. However, parts or organs of plants are more frequently mentioned than those of animals. In addition, the plants in the texts are also mentioned more frequently as life-forms (e.g., tree, shrub). The text analysis also suggests that the emphasis on plants and animals does not differ by the class level or subject area of the textbook.

The photo analysis results resemble the text analysis results. Almost half of the 536 photographs analyzed are photographs of plants, while animal-related photographs have a share of just over one-third. Thus, as in the text analysis, more emphasis was given to plants in the photographs of the textbooks. Landscape and dual-focus photographs are not commonly featured, with a share of $6.52 \%$ and $8.38 \%$, respectively. The photograph analysis also revealed that there is no significant difference in the emphasis of plants and animals across class levels or textbooks.

Wandersee and Schussler $(1999 ; 2001)$ stated in their definition of plant blindness that plants are much less emphasized and valued than animals. Balick and Cox (1996) noted that individuals affected by plant blindness do not focus on or value plants in their daily lives as much as they do animals. Ferguson, Collison, Power and Stevenson (2006) propose that textbooks have contributed significantly to the social, cultural and philosophical worldviews of individuals and their everyday lives. Based on the results of this research, which indicates that there is no large emphasis on either animals or plants in the textbooks analyzed, it can be concluded that the textbooks used at 
the basic education level in Turkey do not ignore plants to such an extent that they contribute to plant blindness in individuals. In fact, in some respects, more emphasis is put on plants than animals.

When both the text and photographs are taken into consideration, there is no significant difference between different subject area textbooks or across class levels in terms of the emphasis put on plants and animals. The general cause of this situation may be directly related to the textbook preparation process in Turkey: textbooks are only approved for use in schools following detailed discussions by experts in their respective fields. Thus, it is thought that the equal focus on plants and animals may be due to the detailed examination and substantial efforts of experts with a common philosophical viewpoint.

Link-Perez, Dollo, Weber and Schussler (2010) examined the photographs in the textbooks analyzing the variable of publishing house and found that animal photographs were used more than plant photographs. The authors stated that this may be directly related to the perspective of the publishers. Different publishing houses may reflect different philosophical and academic views in the textbooks they prepare. Since the textbooks analyzed in the current research are subjected to a single institutional review, this may be the reason why the emphasis on plants and animals does not differ across class levels or subject areas.

When the plant and animal species in the texts are examined, the results obtained indicate that both plants and animals are almost equally represented in terms of species diversity, although the overall number of plant species mentioned is higher. There are examples representing monocotyledons (e.g., wheat, palm) and dicotyledons (e.g., apple tree, tulip), and fish (e.g., anchovies), birds (e.g., chickens, hawks, storks), reptiles (e.g., turtles), mammals (e.g., donkeys, dogs, whales), amphibians (e.g., frogs), and invertebrates (e.g., worms, snails, ants, fireflies). Using species names is more important than indicating "plant" or "animal" because textbooks are an important educational tool in the understanding of the diversity in plants and animals, for learning species names, and for recognizing biodiversity. Therefore, it is thought that it is important to clearly use species names in the textbooks to keep the content rich in diversity. Schussler, Link-Perez, Weber and Dollo (2010) reported that textbooks differ in their use of plant and animal species names; if this is not adequately addressed, these textbooks will be weaker in terms of academic content. The textbooks analyzed in this research do not reflect plant blindness in the text because they present the species diversity of both plants and animals on an almost equal level. A total of 103 species of plants and animals are mentioned in the textbooks. The researchers think that this is sufficient when the class levels of textbooks are taken into consideration. However, non-vascular plant species (e.g. moss) and gymnosperms (e.g. oak, pine) were not commonly mentioned. The inclusion of more examples from these species groups in textbooks is important for a better representation of the species diversity in plants and for preventing plant blindness.

The number of plant and animal species mentioned repeatedly in the text was almost equal. Repeated plant species include apple tree and orange tree; repeated animal species include domestic animals such as cat and dog. The basic education in Turkey covers pre-school education and elementary education. This education is given to children aged 5-10 years old. Berk (2009) emphasizes that children in this age range can take in new knowledge more easily if they are educated from known towards unknown. Moreover, both Piaget $(1929 ; 1960)$ and Vygotsky (1971) emphasized that children in this age range can construct new information based on their daily life experiences and thus it is important to use objects or entities frequently encountered by them in their everyday life in their education. The plants and animals most commonly mentioned are living things that have an important place in the daily life of children. Thus, it is appropriate that more emphasis should be put on these animals and plants so that children can understand new information related to them more easily.

Photographs are an important component of textbooks; some messages can be more easily portrayed using photographs (Golos, Moses \& Wolbers, 2012). In the second stage of the present research, the labels and subjects of photographs were analyzed. It was found that plants are used as subjects of more photographs than animals. This finding is dissimilar to the results reported by Link-Perez, Dollo, Weber and Schussler (2010) and Schussler, Link-Perez, Weber and Dollo (2010). In both previous studies, the authors stated that photographs in the textbooks focus mostly on animals, and the number of photographs of plants is very limited. The authors used this for evidence of plant blindness in textbooks.

In the present research, photographs of plants and animals are more numerous than those of landscapes and dual-focus photographs. It should not be forgotten that photographs in textbooks have a catalytic effect on the processes of learning and comprehension (Mantzicopoulos \& Patrick, 2010). The reflection of individual species from plants and animals alone may be inadequate for reflecting the basic principles of ecology; living things are not independent from their habitats and each other, and portraying them in this way may be restrictive to biology instruction. 
Of the 536 photographs analyzed, 168 plant photographs, 127 animal photographs, 35 landscape photographs and 45 two subject photographs were used without labels. Lack of labeling limits the usefulness of photographs as a source of information in the textbook. Any unlabeled photo may lead to conceptual fallacies, or may be difficult to associate with the text. Martinez-Bello and Martinez-Bello (2016) emphasized that the visuals in textbooks, particularly in early childhood, can make a great contribution to learning. Therefore, it is important that any visuals and visual labels selected for textbooks should be depicted as well as possible to facilitate learning. When the text and visuals in textbooks are appropriately combined, they produce much more effective educational materials (Lemoni, Stamou \& Stamou, 2011).

There are only two photographs depicting parts or organs and they are only of species from plants. There are only 11 photographs categorized as "life-form", all of which are from plants. The absence of photographs categorized as life-forms from animals is a finding concurrent with that of Link-Perez, Dollo, Weber and Schussler (2010). One of the interesting results of this research is the absence of labeled photographs reflecting the category to which the organism belongs (e.g. birds, insects, and open seed plants). This might adversely affect the teaching of subjects such as taxonomy.

Of the labeled photographs, the number of plant species is higher than the number of animal species represented. Similarly, plant species are more often mentioned than animal species in the text. When compared in terms of the number of species, it is seen that while the labeled photographs include fewer species, they are richer in species diversity. There are 69 species of plants and 42 species of animals in the photographs, compared with 51 species of plants and 53 species of animals represented in the text. The diversity of plant species is higher in the photographs than in the text, the reverse is true for animals. Thus, the number of photographs in the textbooks is large enough that plant blindness can be ruled out. This result seems to conflict with the research by Link-Perez, Dollo, Weber and Schussler (2010) and Schussler, Link-Perez, Weber and Dollo (2010); this could be because these studies were conducted on books published in 2010.The newer textbooks analyzed in the current research have been revised in the light of scientific developments during this period; there is a profound historical and cultural background behind textbooks (Issit, 2004).

\section{Educational Implications}

Biology education, which has an important place in science education at the basic education level in Turkey, is focused on living/non-living and plant-animal concepts. Textbooks are the most important tools for teachers teaching these subjects (Fukkink, 2010). Thus, the allocation of equal space to both plants and animals in textbooks is important so that teachers and students can be more informed about the general characteristics of both plants and animals. If animal species garner more focus than plant species, it is inevitable that textbooks will facilitate the concept of "plant blindness" (Uno, 2009). A more effective biology education can be provided if textbooks attach the same importance to the both plants and animals, the number of species represented is increased, and the names of species are repeated more often. The teaching of topics such as adaptation and habitat, which are related to both plants and animals, is of great importance at every level of education. The most important level of education is the basic education. An accurate scientific viewpoint created at this basic level may lead to much more positive outcomes in future education and everyday life. Although this research focuses on textbooks, it should also be remembered by educators that learning through observation of the natural environment may be more important and more effective than anything else.

\section{Conclusions}

The findings of the research showed these textbooks have adopted a balanced approach to plants and animals irrespective of the class level or subject area. Thus, it was concluded that basic education level textbooks in Turkey do not contribute to plant blindness. Similar research should be conducted for different age groups and on different educational shareholders (e.g. curriculum, other visual and printed materials). Moreover, it is clear that there is a need for a new research in social, economic and communicational fields to understand extensively the causes of plant blindness, and offer the reasonable suggestions to prevent this issue. 


\section{References}

Ahi, B., Kurt, I., \& Balci, S. (2017). Hangisi daha akılda kalıcı: Bitki mi? Hayvan mı? Okul öncesi eğitim alan çocukların bitki ve hayvan resimlerini hatırlama durumları. [Which is more permanent: A plant or an animal? Preschool children remembering plant and animal pictures.] Presented in IV. International Eurasian Educational Research Congress (11-14 May 2017, Denizli, Turkey).

Allum, N., Sturgis, P., Tabourazi, D., \& Brunton-Smith, I. (2008). Science knowledge and attitudes across cultures: A meta-analysis. Public Understanding of Science, 17 (1), 35-54.

Baird, J., H., Lazarowitz, R., \& Allman, V. (1984). Science choices and preferences of middle and secondary school students in Utah. Journal of Research in Science Teaching, 21 (1), 47-54.

Balas, B., \& Momsen, J., L. (2014). Attention "blinks" differently for plants and animals. Life Science Education, 13, 437-443.

Balci, S., Ahi, B., \& Gunes, G. (2017). Genç kuşaklar bitki körü mü? İlkokul dördüncü sınıf öğrencilerinin bitki farkındalığı [Young generations plant blind? Plant awareness of fourth grade students in primary school]. Presented 16. International Primary Teacher Education Symposium (8-11 May 2017, Lefke, KKTC)

Balding, M., \& Williams, K., J., H. (2016). Plant blindness and the implications for plant conservation. Conservation Biology, 30 (6), 1192-1199.

Balick, M., J., \& Cox, P., A. (1996). Plants, people, and culture: The science of Ethnobotany. New York: Scientific American Library.

Berk, L., E. (2009). Child development. Boston: Pearson.

Dimopoulos, K., Kouladis, V., \& Sklaveniti, S. (2003). Towards an analysis of visual images in school science textbooks and press articles about science and technology. Research in Science Education, 33 (2), 189-216.

Ferguson, J., Collison, D., Power, D., \& Stevenson, L. (2006). Accounting textbooks: Exploring the production of a cultural and political artifact. Accounting Education: An International Journal, 15 (3), 243-260.

Gatt, S., Tunnicliffe, S., D., Borg, K., \& Lautier, K. (2007). Young Maltese children's ideas about plants. Journal of Biological Education, 41 (3), 117-122.

Golos, D., B., Moses, A., M., \& Wolbers, K., A. (2012). Culture or disability? Examining deaf characters in children's book illustrations. Early Childhood Education Journal, 40, 239-249.

Issitt, J. (2004). Reflections on the study of textbooks. History of Education, 33 (6), 683-696.

Lee, L., \& McMullen, M., B. (2006). Social ideology and early childhood education: A comparative analysis of Korean childhood teacher education textbook written 1993 and 2003. Contemporary Issues in Early Childhood, 7 (2), 119-129.

Lemoni, R., Lefkaditou, A., Stamou, A., G., Schizas, D., \& Stamou, G., P. (2013). Views of nature and the human-nature relations: An analysis of the visual syntax of pictures about the environment in Greek primary school textbook-diachronic considerations. Research in Science Education, 43, 17-140.

Lemoni, R., Stamou, A., G., \& Stamou, G., P. (2011). "Romantic", "classic" and “baraque” views of nature: An analysis of pictures about the environment in Greek primary school textbook-diachronic considerations. Research in Science Education, 41, 811-832.

Lindemann-Matthies, P. (2005). 'Loveable' mammals and 'lifeless' plants: How children's interest in common local organism can be enhanced through observation of nature. International Journal of Science Education, 27 (6), 655-677.

Link-Perez, M., Dollo, V., H., Weber, K., M., \& Schussler, E., E. (2010). What's in a name: Differential labelling of plant and animal photographs in two nationally syndicated elementary science textbook series. International Journal of Science Education, 32 (9), 1227-1242.

Mantzicopoulos, P., \& Patrick, H. (2010). "The seesaw is a machine that goes up and down": Young children's narrative responses to science-related informational text. Early Education and Development, 21 (3), 412-444.

Martinez-Bello, V., \& Martinez-Bello, D. (2016). Depictions of human bodies in the illustrations of early childhood textbooks. Early Childhood Education Journal, 44, 181-190.

Merriam, S. B. (2009). Qualitative research: A guide to design and implementation. CA: Jossey-Bass.

Miralles-Martinez, P., \& Alfageme-Gonzalez, M., B. (2010). The family concept in Spain: Textbooks and students' conceptions. The International Journal of Interdisciplinary Social Sciences, 5 (1), 157-166.

Newton, L., D., \& Newton, D., P. (2006). To what extent can children's geography books help a primary school teacher explain cause and purpose. International Research in Geographical and Environmental Education, 15 (1), $29-40$.

Patrick, P., \& Tunnicliffe, S., D. (2011). What plants and animals do early childhood and primary students' name? Where do they see them? Journal of Science Education and Technology, 20, 630-642.

Piaget, J. (1929/1960). The child's conception of the World. Paterson, NJ: Littlefield, Adams \& Co.

Prochner, L., \& Woitte, S. (2013). Still missing? History chapters in introductory early childhood education textbooks from the 1990s to the 2010s. Journal of Early Childhood Teacher Education, 34, 374-389.

Prokop, P., Prokop, M., \& Tunnicliffe, S., D. (2007). Is biology boring? Students' attitudes toward biology. Journal of Biological Education, 42 (1), 36-39.

Sadava, D., Heller, H. C., Orians, G. H., Purves, W. K., \& Hillis, D. M. (2006). Life: The science of biology (8 $8^{\text {th }}$ Ed.). New York:W. H. Freeman.

Schussler, E., E., \& Olzak, L., A. (2008). It's not easy being green: Students recall of plant and animal images. Journal of Biological Education, 42 (3), 112-118.

Schussler, E., E., \& Winslow, J. (2006). Drawing on students' knowledge. Science and Children, 44 (5), 40-44.

Schussler, E., E., Link-Perez, M., A., Weber, K., M., \& Dollo, V., H. (2010). Exploring plant and animal content in elementary science textbook. Journal of Biological Education, 44 (3), 123-128.

Strgar, J. (2007). Increasing the interest of students in plants. Journal of Biological Education, 42 (1), 19-23.

Sullivan, J., P. (2008). The use of photographs to portray urban ecosystem in six introductory environmental science textbooks. 
Journal of Research in Science Teaching, 45 (9), 1003-1020.

Thompson, T., L., \& Mintzes, J., J. (2002). Cognitive structure and the affective domain: On knowing and feeling in biology. International Journal of Science Education, 24 (6), 645-660.

Tunnicliffe, S., D., \& Reiss, M., J. (2000). Building a model of the environment: How do children see plants? Journal of Biological Education, 34 (4), 172-177.

Uno, G., E. (1994). The state of precollege botanical education. The American Biology Teacher, 56 (5), 263-267.

Uno, G., E. (2009). Botanical literacy: What and how should students learn about plants? American Journal of Botany, 96 (10), 1753-1759.

Vygotsky, L. S. (1971). The psychology of art. Cambridge: The MIT Press.

Wandersee, J., H. (1986). Plants or animals - Which do junior high school students prefer to study? Journal of Research in Science Teaching, 23 (5), 415-426.

Wandersee, J., H., Schussler, E., E. (1999). Preventing plant blindness. The American Biology Teacher, 61 (2), 82-86.

Wandersee, J., H., Schussler, E., E. (2001). Toward a theory of plant blindness. Plant Science Bulletin, 47 (1), 2-9.

Yorek, N., Sahin, M., \& Aydin, H. (2009). Are animals'more alive'than plants? Animistic-antrophocentric construction of life concept. Eurasia Journal of Mathematics, Science \& Technology Education, 5 (4), 369-378.

Berat Ahi

Volkan Atasoy

Sibel Balci
PhD, Kastamonu University, Faculty of Education, Department of Preschool Education, Kastamonu 37200 Turkey.

E-mail: beratahi@gmail.com

PhD, Kastamonu University, Faculty of Education, Department of Preschool Education, Kastamonu 37200 Turkey.

E-mail: vatasoy5@gmail.com

PhD, Associate Professor, TED University, Department of Basic

Education, Ankara, 06340 Turkey.

E-mail: sibel.balci@gmail.com 